ORIGINAL RESEARCH

\title{
Injuries In Mountain Bike Racing: Frequency of Injuries In Endurance Versus Cross Country Mountain Bike Races
}

\author{
Stephanie A. Lareau, MD; Henderson D. McGinnis, MD \\ From the Department of Emergency Medicine, Wake Forest University Baptist Medical Center, Winston-Salem, NC (Drs Lareau and \\ McGinnis).
}

\begin{abstract}
Objective.-To determine the frequency of injuries requiring medical attention among mountain bike racers at endurance races ( 6 hours or greater in duration) versus traditional cross country races (less than 6 hours duration) and to determine the medical support available at races.

Methods.-A survey was developed to determine participants' experience level, previous injuries, and demographic information. An additional survey was completed by injured riders to determine injuries and treatment received. The number of medical providers, their level of training, and the supplies available was determined.

Results.-The endurance riders had more years of mountain biking experience, averaged more hours of riding per week, and had fewer injuries requiring medical attention in the past year than the riders in the races. Of the cross-country riders, $7.2 \%$ were injured during the race, and $4.7 \%$ of endurance racers were injured. There was no increased risk of being injured in a race over an endurance race (odds ratio $1.6,95 \% \mathrm{CI}[0.50,2.92])$. Lacerations and abrasions were the most common injuries in both events. Head injuries, eye injuries, and blisters were only reported in the endurance events. Endurance events were more likely to have medical assistance available.

Conclusion.- - There was a greater percentage of riders reporting injuries in the cross-country races. It is possible that many of the endurance racers did not report injuries, continuing to ride or taking care of their own injuries quickly. Both events tended to have similar types of injuries and, therefore, both events most likely need similar medical support.
\end{abstract}

Key words: mountain biking, mountain bike racing, mountain bike injuries, endurance events

\section{Introduction}

Mountain biking and mountain bike racing are very popular sports. It is estimated that approximately 50 million Americans mountain bike. While most enjoy mountain biking as a recreational sport, competitive mountain biking is also a growing sport. In 2009, there were 451 mountain bike events out of 2638 events sanctioned by USA Cycling (the official organizing body that encompasses mountain biking, formerly NORBA [National Off Road Bicycle Association]). There are many more local and regional events that are not USA Cyclingsanctioned. Mountain bike races, referred to as crosscountry races, are 1 - to 4 -hour events in which riders

Corresponding author: Stephanie Lareau, MD, Department of Emergency Medicine, Wake Forest University Baptist Medical Center, Medical Center Blvd, Winston-Salem, NC 27157 (e-mail: StephLareau@ gmail.com) complete one or more laps of a course to complete a set distance. The rider who completes this set distance in the shortest amount of time wins. As mountain biking has evolved, a new type of event has become popular where individuals or relay teams attempt to cover the most distance (or laps) in a set period of time. These races typically span from 6 to 24 hours and are considered endurance races. The tactics vary among the genres of racing depending on the terrain, skill levels, and amount of distance riders plan to cover.

Due to the technical terrain, physical and mental fatigue, and rider error, both cross-country and endurance mountain biking can be potentially dangerous sports resulting in injuries ranging in severity from minor abrasions and bruises to paralysis or even death. When riding recreationally, riders must take their own safety into account. However, when paying to participate in an event, many feel that the event organizer has a respon- 
sibility to ensure the safety of the participants by providing medical support.

Currently, the governing body of mountain biking, USA Cycling, provides a generic form that can be used as a template to create a medical plan for the event. They recognize "Competitive bicycling can be a very exciting and fast-paced sport full of action, thrills and even spills. In planning an event, event directors and their staffs must consider not only how they will handle minor injuries such as cuts and bruises, but also major catastrophic injuries that will require full attention from trained medical personnel." 1

It is difficult to determine the injury rate for participants in both cross-country mountain bike races and endurance mountain bike races since there is no central registry for accidents. Also, there have been no large studies of injuries sustained by participants in endurance mountain bike races even through these races are increasingly popular. We sought to determine the number of injuries sustained during a series of both cross-country and endurance mountain bike races in the southeastern United States. By comparing the 2 kinds of races, we hoped to be able to provide race organizers information about the incidence and type of injuries that they should be prepared to encounter and, in addition, provide information about the kinds of medical support available at other cycling events.

\section{Methods}

\section{STUDY DESIGN}

A survey (Appendix 1, Available online at www. wemjournal.org) was designed to assess the riders' experience level, previous injuries, and pre-existing medical conditions as well as basic demographic information. The survey was distributed to riders as part of the onsite registration process prior to the beginning of the race.

An additional survey (Appendix 2, Available online at www.wemjournal.org) was completed by injured riders either at the time of the injury or at the completion of the race. This survey assessed the type of injury, injury mechanism, the treatment received, and if the injury resulted in the rider withdrawing from the race. The kinds of injuries included on the survey included abrasions, lacerations, contusions, closed fractures, open fractures, sprains/strains, insect bites, and pre-existing medical conditions.

Prior to the events, the medical personnel present were surveyed (Appendix 3, Available online at www. wemjournal.org) to determine the number of medical providers, the level of medical training, and the supplies available onsite. This survey was completed by medical personnel, if available, or by the study personnel based on information from the event organizer if no medical personnel were present.

This project was approved by the Wake Forest University School of Medicine Internal Review Board. The requirement for informed consent was waived.

\section{STUDY POPULATION}

Survey respondents included 448 riders at 6 mountain bike races in North Carolina and Georgia, including two 2 cross-country races (less than 6 hours), two 6- to 12-hour races, and two 24-hour races during a 6-month period. The races were divided into cross-country (less than 6 hours) and endurance (greater than 6 hours) for comparison. Participation in the survey varied from $38 \%$ to $87 \%$. Participation varied greatly based on the structure of the registration process, as in some events the survey was distributed as a part of registration and at other events it was separate.

\section{STUDY PROTOCOL}

All race participants were given the option to complete the survey at race registration. Surveys of injured riders were given to all riders seeking medical attention (where available) and to riders who were obviously injured when crossing the finish line. On several occasions, the obviously injured riders submitted surveys regarding their injury but did not complete the initial demographics survey.

For this analysis, the 6- to 12-hour races and the 24-hour races were combined as endurance races and were compared to the traditional cross-country races. They were combined because many of the 12- and 24hour races were done as teams (2-person and 4-person, respectively, who split the riding time), meaning the riders each participated in 6 or more hours of the event. Cross-country races uniformly took participants less than 6 hours to complete.

Data was entered into a Microsoft Excel (Microsoft Corporation, Redmond, CA) spreadsheet and analysis was performed using standard descriptive statistics. The univariate odds ratios were calculated to determine the relationship between being injured in a cross country versus endurance race.

\section{Results}

A total of 448 surveys were completed in the 6 events. Of these riders, 212 competed in 24-hour races, 125 competed in the 6- to 12-hour races, and 111 competed in the cross-country races. 
Table 1. First aid supplies

\begin{tabular}{|c|c|c|c|c|c|c|}
\hline Supplies & Cross Country \#1 & Cross Country \#2 & $12 / 6 \mathrm{~h} \mathrm{\# 1}$ & $12 / 6 h \# 2$ & $24 h \# 1$ & $24 h \# 2$ \\
\hline Bandaids & $\mathrm{x}$ & & $\mathrm{x}$ & $\mathrm{x}$ & $\mathrm{x}$ & $\mathrm{x}$ \\
\hline Gauze pads & $\mathrm{x}$ & & $\mathrm{x}$ & $\mathrm{x}$ & $\mathrm{x}$ & $\mathrm{x}$ \\
\hline Adhesive tape & $\mathrm{x}$ & & $\mathrm{x}$ & $\mathrm{x}$ & $\mathrm{x}$ & $\mathrm{x}$ \\
\hline Ice/cold packs & $\mathrm{x}$ & & $\mathrm{x}$ & $\mathrm{x}$ & $\mathrm{x}$ & $\mathrm{x}$ \\
\hline Ace bandages & $\mathrm{x}$ & & $\mathrm{x}$ & $\mathrm{x}$ & $\mathrm{x}$ & $\mathrm{x}$ \\
\hline Alcohol wipes & $\mathrm{x}$ & & $\mathrm{x}$ & $\mathrm{x}$ & $\mathrm{x}$ & $\mathrm{x}$ \\
\hline Water & $\mathrm{x}$ & & $\mathrm{x}$ & $\mathrm{x}$ & $\mathrm{x}$ & $\mathrm{x}$ \\
\hline Soap & $\mathrm{x}$ & & $\mathrm{x}$ & $\mathrm{x}$ & $\mathrm{x}$ & $\mathrm{x}$ \\
\hline Gloves & $\mathrm{x}$ & & $\mathrm{x}$ & $\mathrm{x}$ & $\mathrm{x}$ & $\mathrm{x}$ \\
\hline Pressure dressing & & & $\mathrm{x}$ & & $\mathrm{x}$ & $\mathrm{x}$ \\
\hline Eye wash & $\mathrm{x}$ & & $\mathrm{x}$ & $\mathrm{x}$ & $\mathrm{x}$ & $\mathrm{x}$ \\
\hline $\begin{array}{l}\text { Antibiotic } \\
\text { ointment }\end{array}$ & $\mathrm{x}$ & & $\mathrm{x}$ & $\mathrm{x}$ & $\mathrm{x}$ & $\mathrm{x}$ \\
\hline Insect bite relief & $\mathrm{x}$ & & $\mathrm{x}$ & $\mathrm{x}$ & $\mathrm{x}$ & \\
\hline Scissors & & & $\mathrm{x}$ & $\mathrm{x}$ & $\mathrm{x}$ & $\mathrm{x}$ \\
\hline Sunscreen & & & $\mathrm{x}$ & $\mathrm{x}$ & $\mathrm{x}$ & $\mathrm{x}$ \\
\hline Safety pins & & & $\mathrm{x}$ & $\mathrm{x}$ & $\mathrm{x}$ & $\mathrm{x}$ \\
\hline Quick splints & & & & & $\mathrm{x}$ & $\mathrm{x}$ \\
\hline Tweezers & & & $\mathrm{x}$ & $\mathrm{x}$ & $\mathrm{x}$ & \\
\hline CPR faceshield & & & $\mathrm{x}$ & $\mathrm{x}$ & $\mathrm{x}$ & \\
\hline C-collar & & & & & $\mathrm{x}$ & $\mathrm{x}$ \\
\hline Backboard & & & & & $\mathrm{x}$ & $\mathrm{x}$ \\
\hline AED & & & & & $\mathrm{x}$ & $\mathrm{x}$ \\
\hline Glucometer & & & & & $\mathrm{x}$ & $\mathrm{x}$ \\
\hline Ambulance & & & & & $\mathrm{x}$ & $\mathrm{x}$ \\
\hline Bag-valve mask & & & & & $\mathrm{x}$ & $\mathrm{x}$ \\
\hline \multicolumn{7}{|l|}{ Drugs } \\
\hline EpiPen & & & & & $\mathrm{x}$ & $\mathrm{x}$ \\
\hline Aspirin & & & & & $\mathrm{x}$ & $\mathrm{x}$ \\
\hline Nitroglycerin & & & & & $\mathrm{x}$ & $\mathrm{x}$ \\
\hline Benedryl & & & & & $\mathrm{x}$ & $\mathrm{x}$ \\
\hline Glucagon & & & & & $\mathrm{x}$ & $\mathrm{x}$ \\
\hline Oxygen & & & & & $\mathrm{x}$ & $\mathrm{x}$ \\
\hline Asthma inhaler & & & & & $\mathrm{x}$ & $\mathrm{x}$ \\
\hline \multicolumn{7}{|l|}{ Personnel } \\
\hline CPR certified staff & & & $\mathrm{x}$ & & $\mathrm{x}$ & $\mathrm{x}$ \\
\hline EMT/RN & & & & $\mathrm{x}$ & $\mathrm{x}$ & $\mathrm{x}$ \\
\hline \multicolumn{7}{|l|}{ Physicians } \\
\hline First aid certified & & & $\mathrm{x}$ & & $\mathrm{x}$ & \\
\hline
\end{tabular}

All 6 events were surveyed regarding available medical support. Three of the endurance events provided visible medical personnel and supplies, and one of the endurance events provided only a first aid kit. One of the cross-country races provided a first aid kit and the other cross-country race provided no first aid provisions. (Please refer to Table 1 for further information).

A total of 8 injuries were sustained in the crosscountry races, and 17 injuries in the endurance races. The rate of injury was $7.2 \%$ in the cross-country races and $4.7 \%$ in the endurance races. The overall injury rate was
$5.4 \%$. There was no increased risk for being injured in a cross-country race over an endurance race (odds ratio $1.6,95 \%$ CI $[0.50,2.92])$.

In the cross-country races, $75 \%$ (6) of injuries were classified as abrasions/lacerations, $12.5 \%$ (1) as sprains/ strains, and $12.5 \%$ (1) as contusions.

In the endurance races, as seen in Table 2, 60\% (10) of the injuries were classified as abrasions/lacerations, $13 \%$ (2) were head injuries, $6.7 \%$ (1) were strain/sprains, $6.7 \%$ (1) involved foreign bodies in the eye, and $13.3 \%$ (2) were blisters. 
Table 2. Demographics of injured riders

\begin{tabular}{|c|c|c|c|c|c|c|c|c|c|}
\hline$\#$ & Race & Injury type & Injury location(s) & $\begin{array}{c}\text { Race } \\
\text { Ending? }\end{array}$ & Gender & $\begin{array}{c}\text { Years } \\
\text { mountain } \\
\text { biking }\end{array}$ & $\begin{array}{l}\text { Years } \\
\text { racing }\end{array}$ & $\begin{array}{l}\text { Hours } \\
\text { per } \\
\text { week } \\
\text { riding }\end{array}$ & $\begin{array}{c}\text { Injuries with } \\
\text { medical } \\
\text { attention in } \\
\text { past year }\end{array}$ \\
\hline 1 & Cross Country \#1 & contusion & gluteus & no & female & $1-3$ & $<1$ & $6-8$ & 0 \\
\hline 2 & Cross Country \#1 & laceration, abrasion & $\begin{array}{l}\text { elbow, rib, arm, } \\
\text { head }\end{array}$ & no & male & $5+$ & $<1$ & $4-6$ & 3 \\
\hline 3 & Cross Country \#1 & abrasion & $\operatorname{shin}$ & no & male & $<1$ & $<1$ & $4-6$ & 1 \\
\hline 4 & Cross Country \#1 & abrasion, contusion & knee, trunk, thumb & no & male & $5+$ & $1-3$ & $2-4$ & 3 \\
\hline 5 & Cross Country \#1 & abrasion, laceration & skin, ribs & no & female & $5+$ & $3-5$ & $2-4$ & 0 \\
\hline 1 & Cross Country \#2 & laceration & knee, elbow & no & - & - & - & - & - \\
\hline 2 & Cross Country \#2 & strain & back & no & - & - & - & - & - \\
\hline 3 & Cross Country \#2 & laceration & knee, elbow & no & - & - & - & - & - \\
\hline 1 & 12/6h \#1 & concussion & head & yes & male & $5+$ & $<1$ & $2-4$ & 2 \\
\hline 2 & 12/6h \#1 & abrasion, laceration & arm, finger & yes & male & $1-3$ & $<1$ & $2-4$ & 1 \\
\hline 3 & 12/6h \#1 & abrasion & arm, shin & no & male & $5+$ & $3-5$ & $<2$ & 0 \\
\hline 4 & 12/6h \#1 & abrasion & elbow, knee & no & male & $1-3$ & $<1$ & $8-10$ & 0 \\
\hline 5 & 12/6h \#1 & sprain & arm, wrist & no & male & $5+$ & $5+$ & $6-8$ & 2 \\
\hline 1 & 24h \#1 & abrasion & elbow, knee & no & female & $1-3$ & $1-3$ & $6-8$ & 0 \\
\hline 2 & 24h \#1 & abrasion & arm & no & female & $5+$ & $1-3$ & $2-4$ & 0 \\
\hline 3 & 24h \#1 & abrasion & arm & no & - & - & - & - & - \\
\hline 4 & 24h \#1 & abrasion & elbow, shin & no & male & $5+$ & $5+$ & $<2$ & 0 \\
\hline 5 & 24h \#1 & laceration & knee & no & male & $5+$ & $3-5$ & $2-4$ & 0 \\
\hline 6 & 24h \#1 & blister & hand & no & male & $5+$ & $5+$ & $2-4$ & 0 \\
\hline 7 & 24h \#1 & blister & hand & yes & male & $5+$ & $5+$ & $8-10$ & 0 \\
\hline 1 & 24h \#2 & abrasion & calf & no & male & $5+$ & $5+$ & $10+$ & 0 \\
\hline 2 & $24 \mathrm{~h} \# 2$ & abrasion & thigh, shin & no & male & $3-5$ & $1-3$ & $6-8$ & 1 \\
\hline 3 & 24h \#2 & concussion & head & yes & male & $3-5$ & $1-3$ & $4-6$ & 0 \\
\hline 4 & $24 \mathrm{~h} \# 2$ & dust & eye & no & male & $5+$ & $5+$ & $8-10$ & 0 \\
\hline \multicolumn{10}{|c|}{ (- indicates information was not reported by rider) } \\
\hline
\end{tabular}

As seen in Table 3, in both types of events the breakdown between males and females was similar (endurance $82.7 \%$ male, $17.2 \%$ female, cross-country $83.9 \%$ male, $16.1 \%$ female). The endurance riders tended to have more years of experience riding, as $66.6 \%$ reported mountain biking for greater than 5 years, whereas only $52 \%$ of cross-country racers reported riding for greater than 5 years. It is also notable that the endurance racers had more racing experience, with $37.1 \%$ racing for greater than 5 years and only $19.6 \%$ having raced less than 1 year; whereas in the cross country racing, only $21.6 \%$ of riders had greater than 5 years of racing experience and $32.4 \%$ of riders had less than one year of experience. More crosscountry riders tended to have injuries requiring medical attention in the past year $(30 \%)$ than the endurance racers $(21 \%)$. This was despite similar reported hours of riding weekly.

\section{Discussion}

Typically, one might expect that riders would suffer a greater number of injuries in a 24-, 12-, or 6-hour race than in a shorter cross-country race simply based on the number of hours spent riding. The injuries per hour could not be calculated from this data since many riders completed the endurance events as members of teams. Endurance racing introduces a greater amount of fatigue. In some cases, endurance racers compete in the dark using helmet- and handlebar-mounted lights. These considerations likely prompt race promoters at endurance events to provide more extensive medical support, as seen through this sample of 6 events. All 4 endurance events provided at least a first aid kit. Three of the endurance events also provided a first aid station. One of the 24hour events had a mobile EMS event trailer set up with personnel with an ATV able to reach injured riders at any point on the course. 
Table 3. Demographic information

\begin{tabular}{|c|c|c|c|c|c|c|c|c|c|c|c|c|c|c|c|c|}
\hline \multirow[b]{2}{*}{ Gender } & \multicolumn{2}{|c|}{$\begin{array}{l}24 \text { hour } \\
\text { race \#1 }\end{array}$} & \multicolumn{2}{|c|}{$\begin{array}{l}24 \text { hour } \\
\text { race \#2 }\end{array}$} & \multicolumn{2}{|c|}{$\begin{array}{l}\text { 12/6 hour } \\
\text { race \#1 }\end{array}$} & \multicolumn{2}{|c|}{$\begin{array}{l}\text { 12/6 hour } \\
\text { race \#2 }\end{array}$} & \multicolumn{2}{|c|}{$\begin{array}{c}\text { Cross } \\
\text { Country } \\
\# 1\end{array}$} & \multicolumn{2}{|c|}{$\begin{array}{c}\text { Cross } \\
\text { Country } \\
\# 2\end{array}$} & \multicolumn{2}{|c|}{$\begin{array}{c}\text { Totals: } \\
\text { Endurance }\end{array}$} & \multicolumn{2}{|c|}{$\begin{array}{l}\text { Totals: } \\
\text { Cross } \\
\text { Country }\end{array}$} \\
\hline & & $\%$ & & $\%$ & & $\%$ & & $\%$ & & $\%$ & & $\%$ & & $\%$ & & $\%$ \\
\hline Male & 33 & 78.6 & 147 & 86.5 & 52 & 78.8 & 45 & 76.3 & 43 & 81.1 & 51 & 87.9 & 277 & 82.7 & 94 & 84.7 \\
\hline Female & 9 & 21.4 & 21 & 12.4 & 14 & 21.2 & 14 & 23.7 & 11 & 20.8 & 7 & 12.1 & 58 & 17.3 & 18 & 16.2 \\
\hline \multicolumn{17}{|c|}{ Years mountain biking } \\
\hline$<1$ & 2 & 4.8 & 5 & 2.9 & 4 & 6.1 & 4 & 6.8 & 4 & 7.5 & 6 & 10.3 & 15 & 4.5 & 10 & 9.0 \\
\hline $1-3$ & 2 & 4.8 & 22 & 12.9 & 10 & 15.2 & 6 & 10.2 & 3 & 5.7 & 10 & 17.2 & 40 & 11.9 & 13 & 11.7 \\
\hline $3-5$ & 6 & 14.3 & 29 & 17.1 & 14 & 21.2 & 8 & 13.6 & 16 & 30.2 & 13 & 22.4 & 57 & 17.0 & 29 & 26.1 \\
\hline $5+$ & 32 & 76.2 & 110 & 64.7 & 38 & 57.6 & 41 & 69.5 & 29 & 54.7 & 29 & 50.0 & 221 & 66.0 & 58 & 52.3 \\
\hline \multicolumn{17}{|c|}{ Years racing } \\
\hline$<1$ & 3 & 7.1 & 33 & 19.4 & 23 & 34.8 & 7 & 11.9 & 16 & 30.2 & 20 & 34.5 & 66 & 19.7 & 36 & 32.4 \\
\hline $1-3$ & 8 & 19.0 & 33 & 19.4 & 12 & 18.2 & 14 & 23.7 & 9 & 17.0 & 17 & 29.3 & 67 & 20.0 & 26 & 23.4 \\
\hline $3-5$ & 9 & 21.4 & 37 & 21.8 & 13 & 19.7 & 18 & 30.5 & 15 & 28.3 & 10 & 17.2 & 77 & 23.0 & 25 & 22.5 \\
\hline $5+$ & 22 & 52.4 & 65 & 38.2 & 18 & 27.3 & 20 & 33.9 & 13 & 24.5 & 11 & 19.0 & 125 & 37.3 & 24 & 21.6 \\
\hline \multicolumn{17}{|c|}{ Hours riding per week } \\
\hline$<2$ & 6 & 14.3 & 11 & 6.5 & 3 & 4.5 & 4 & 6.8 & 7 & 13.2 & 2 & 3.4 & 24 & 7.2 & 9 & 8.1 \\
\hline $2-4$ & 18 & 42.9 & 26 & 15.3 & 20 & 30.3 & 10 & 16.9 & 9 & 17.0 & 21 & 36.2 & 74 & 22.1 & 30 & 27.0 \\
\hline $4-6$ & 5 & 11.9 & 46 & 27.1 & 18 & 27.3 & 21 & 35.6 & 12 & 22.6 & 16 & 27.6 & 90 & 26.9 & 28 & 25.2 \\
\hline $6-8$ & 5 & 11.9 & 26 & 15.3 & 8 & 12.1 & 7 & 11.9 & 12 & 22.6 & 9 & 15.5 & 46 & 13.7 & 21 & 18.9 \\
\hline $8-10$ & 4 & 9.5 & 27 & 15.9 & 8 & 12.1 & 7 & 11.9 & 4 & 7.5 & 4 & 6.9 & 46 & 13.7 & 8 & 7.2 \\
\hline $10+$ & 4 & 9.5 & 34 & 20.0 & 9 & 13.6 & 10 & 16.9 & 9 & 17.0 & 6 & 10.3 & 57 & 17.0 & 15 & 13.5 \\
\hline \multicolumn{17}{|c|}{ Times injured with medical attention in past year } \\
\hline 0 & 34 & 81.0 & 128 & 75.3 & 50 & 75.8 & 53 & 89.8 & 37 & 69.8 & 40 & 69.0 & 265 & 79.1 & 106 & 69.4 \\
\hline 1 & 4 & 9.5 & 21 & 12.4 & 6 & 9.1 & 3 & 5.1 & 10 & 18.9 & 11 & 19.0 & 34 & 10.1 & 29 & 18.9 \\
\hline 2 & 2 & 4.8 & 8 & 4.7 & 5 & 7.6 & 2 & 3.4 & 5 & 9.4 & 5 & 8.6 & 17 & 5.1 & 14 & 9.0 \\
\hline 3 & 0 & 0.0 & 8 & 4.7 & 1 & 1.5 & 1 & 1.7 & 0 & 0.0 & 2 & 3.4 & 10 & 3.0 & 3 & 1.8 \\
\hline 4 & 1 & 2.4 & 3 & 1.8 & 2 & 3.0 & 0 & 0.0 & 0 & 0.0 & 0 & 0.0 & 6 & 1.8 & 0 & 0.0 \\
\hline$>5$ & 1 & 2.4 & 1 & 0.6 & 2 & 3.0 & 0 & 0.0 & 1 & 1.9 & 0 & 0.0 & 4 & 1.2 & 1 & 0.9 \\
\hline
\end{tabular}

Interestingly, the incidence of injuries reported was actually higher at the shorter cross-country races. By looking at the rider data, when compared to the cross country racers, the endurance racers tended to have more race and riding experience. The endurance racers also reported fewer injuries requiring medical attention over the past year. It is, therefore, possible that there are fewer injuries at endurance races because the racer population is more experienced overall and less injury-prone.

The tactics involved in endurance racing and crosscountry racing also differ. In cross-country races, riders typically ride for a predetermined distance. Since the races are short, the intensity at which riders compete may be higher. In endurance races, riders have a set amount of time and the winner is the one who completes the greatest distance in the allotted time. The mindset of these riders differs, as they are required to pace themselves over a longer period of time. It is possible, therefore, that these riders may ride with lower average speeds, as they know they need to be able to ride for a greater period of time.
Endurance racers often set up tents and provide their own support staff when they compete. Since only riders coming to the race-organized first aid areas were surveyed, it is possible that some injuries among endurance racers were cared for away from the central race area and, therefore, were not reported. For example, if a rider scraped his/her knee during the first hour of an endurance race, but continued to ride, it is unlikely he/she would mention this; whereas, if he/she scraped his/her knee near the end of the cross-country race after finishing, he/she would be more likely to get some first aid supplies before driving home.

The kinds of injuries reported were similar. Both events had a predominance of abrasions and lacerations. This occurrence confirms previous research that indicated these were the most common injuries to occur in mountain biking. ${ }^{2-7}$ Blisters, head injuries, and eye injuries were only reported at the endurance events. The eye injury reported was dust in the eyes, which was more likely related to course conditions than the length of the race. The blisters were not reported until late in the race, 
so they may be attributed to the longer duration of riding. In riding, head injuries typically occur when a rider flips over the handlebars, referred to as an "endo." In our sample, these only occurred during endurance events, possibly due to rider fatigue. Contusions were only reported in the cross-country races. It is suspected that most riders in the endurance events did not seek assistance for this sort of injury.

This study could be improved by surveying all participants after the races to better capture all injuries. The goal of the study was to provide information to race-promoters about injuries occurring specifically in endurance races compared with cross-country races. Race-promoters do not necessarily need to be prepared to provide medical care to riders who do not seek care or acknowledge an injury; therefore, our sample is representative of the riders who may require or desire first aid assistance.

From the injuries seen at these 6 events, it appears that there is no statistically significant difference in the odds ratio of sustaining an injury at an endurance race versus at a cross country race. In examining the support provided in our sample, it appears that endurance race promoters are often already prepared, whereas the 2 cross-country races in our sample had fewer first aid provisions. Promoters should make decisions about onsite medical support by taking into account proximity to definitive medical care and terrain covered. ${ }^{8}$ It appears that the length of the race does not alter the support needed, which is contrary to what appears to occur at races; the longer endurance races tend to be better equipped to handle both minor and major emergencies.

Notably, at the 6 events that were attended, no potentially life-threatening emergencies were identified that required EMS transportation. No one suffered a medical emergency requiring immediate life-saving measures, and it is unlikely anyone suffered an adverse outcome from lack of medical provisions. Therefore, with this sample, it is impossible to comment on the incidence of life-threatening injuries or suggest a definite need for resuscitation capabilities at events.

\section{Limitations}

This study has several limitations. Participation in the demographic information collection was variable from $38 \%$ to $87 \%$ depending on the intricacies of the onsite registration process, which were variable. In several incidences, injured riders did not fill out the demographics information. Also, the only injuries recorded were from people who sought first aid support or who self-reported injuries at our table located at the start/finish area. At both types of events, there were riders who were clearly injured (visible abrasions) who did not report injuries. Therefore, the incidence of minor injury is likely much higher.

The study could be improved by expanding it to include a greater number of events, especially cross-country events. The study was only conducted in the southeastern states, which geographically have similar terrain and, therefore, the results may not be applicable to all of the varieties of mountain bike terrain. There were no measures taken to ensure that riders who competed in multiple events did not complete multiple surveys.

\section{Conclusions}

In the races we surveyed, very few riders were injured and the majority of the injuries sustained were minor. The duration of the race did not significantly impact the incidence of injuries. Medical support varied drastically between events. A larger survey including a greater number of events is needed to determine the level of medical support needed for mountain biking events.

\section{Acknowledgments}

This research was supported by the Laura Scales Memorial Fund, Wake Forest Medical Student Summer Research Grant, Wake Forest University School of Medicine.

\section{Supplementary Data}

Supplementary data, Appendices 1-3, for this article can be found in the online version (available at www.wemjournal. org).

\section{References}

1. International Mountain Biking Association. Available at: http://www.imba.com/. Accessed February 22, 2006.

2. Carmont MR. Mountain bike injuries: a review. $\mathrm{Br} \mathrm{Med}$ Bull. 2008;85:101-112.

3. Chow TK, Bracker MD, Patrick K. Acute injuries from mountain biking. West J Med. 1993;159:145-148.

4. Kronisch RL, Pfeiffer RP. Mountain biking injuries: an update. Sports Med. 2002;32:523-537.

5. Chow TK, Kronische RL. Mechanisms of injury in competitive off-road bicycling. Wilderness Environ Med. 2002;13:27-30.

6. Rivara FP, Thompson DC, Thompson RS, Rebolledo V. Injuries involving off-road cycling. J Fam Pract. 1997;44: 481-485.

7. Pfeiffer RP. Off-road bicycle racing injuries - the NORBA Pro/Elite category. Care and Prevention. Clin Sports Med. 1994;13:207-218.

8. Carmont MR, Daynes R, Sedgewick DM. The impact of an extreme sports event on a district hospital. Scott Med J. 2005;50:106-108. 
Appendix 1. Rider profile: analysis of injuries in endurance mountain bike events

1. Race Number

2. Initials

3. Check your race category.

$\square$ solo

$\square$ two person team

$\square$ four person team

$\square$ five + person team

4. Will you be racing at night? (If no skip to item 7)

$\square$ Yes $\square$ No

5. What type of light setup do you plan to use?

$\square$ handlebar mount $\square$ helmet mount

$\square$ taillight $\quad \square$ other

6. In the past month how many times have you ridden at night using lights?

$\square$ none $\square$ 1-2 $\square 3-4 \quad \square 5+$

7. What type of bike setup will you use for this race?

Frame?

$\square$ hardtail (front suspension) $\square$ rigid (no suspension)

$\square$ full suspension $\left(<3.5^{\prime \prime}\right) \quad \square$ single speed

$\square$ full suspension ( $\left.>3.5^{\prime \prime}\right) \quad \square$ fixed gear

Pedals?

$\square$ clipless pedals $\square$ toe clips

$\square$ flat pedals $\quad \square$ other

Brakes?

$\square$ V-brakes $\quad \square$ disc brakes

$\square$ cantilever brakes $\square$ other

8. What personal gear will you use during the race? (check all that apply)

$\square$ helmet

$\square$ MP3 player/music

$\square$ gloves

$\square$ shin guards

$\square$ knee pads

$\square$ elbow pads

$\square$ hydration pack (camelbak) $\square$ cell phone

$\square$ walkie talkie (radio)

9. How many years have you been mountain biking?

$\square<1 \square$ 1-3 $\square 3-5 \square 5+$ (specify) years

10. How many years have you raced mountain bikes?

$\square<1 \square$ 1-3 $\square 3-5 \square 5+$ (specify) years

11. Based on the NORBA classification used for mountain biking what is your class?
Never raced
$\square$ Beginner
$\square$ Sport
$\square$ Pro

$\square$ Expert

$\square$ Semi-Pro

12. How many endurance mountain events have you competed in?

(endurance events span 6 to 24 hours)

$\square$ this is my first $\square$ 1-2 $\square 3-5$

$\square 6-10$

$\square 11-19 \quad \square 20+$
13. On average about how many hours per week do you spend mountain biking?
$\square<2$
$\square 2-4 \quad \square 4-6$
$\square 6-8 \quad \square 8-10 \quad \square 10+$

14. How many times have you been injured (requiring medical attention) in the past year?
$\square$ none $\square 1 \quad \square 2$
$\square 3 \quad \square 4 \quad \square>5$

Explain

15. Check all injuries that you have sustained biking in the past 6 months that prevented you for riding for one week? (Check body part and circle all injuries that apply)

$\square$ none

wrist sprain/strain fracture cut scrape bruise arm sprain/strain fracture cut scrape bruise shoulder sprain/strain fracture cut scrape bruise leg sprain/strain fracture cut scrape bruise ankle sprain/strain fracture cut scrape bruise knee sprain/strain fracture cut scrape bruise head concussion fracture cut scrape hand sprain/strain fracture cut scrape bruise other (please specify)

17. Do you have first aid supplies for yourself/team? $\square$ yes $\square$ no

18. Check any pre-existing medical conditions you have:

$\square$ none $\quad \square$ hypertension

$\square$ diabetes $\square$ heart murmur

$\square$ asthma $\quad \square$ allergy to bee sting

$\square$ epilepsy $\square$ other

19. Have you provided any medical information to the race staff?

$\square$ yes $\square$ no

If yes indicate

20. Have you had a physical exam in the past year?

$\square$ yes $\square$ no

21. Indicate your age
$\square<18 \quad \square 18-23$
$\square 36-40 \quad \square 41-45 \quad \square 46-50 \quad \square 51-55$
$\square 56-60 \quad \square 61+$

22. Indicate your gender

$\square$ female $\square$ male

23. Indicate your highest education level

$\square$ some high school $\square$ high school $\square$ some college

$\square$ associate's degree $\square$ bachelor's degree

$\square$ some graduate school $\square$ graduate degree 
Appendix 2. Analysis of injuries in endurance mountain bike events

\author{
Race number \\ Class \\ Initials \\ Time (eg,1:30 pm) \\ Hours into event \\ Hours riding \\ Daylight \\ Race ending
}

Location
Downhill
Rocky
Rooty
Corner
Log
Stream
Other
Injury
Abrasion
Laceration
Contusion
Closed fracture
Open fracture
Sprain/strain
Insect bite
Pre-existing medical
Other
Location Of Injury
Hand
Wrist
Arm
Elbow
Head
Neck
Shoulder
Thigh
Knee
Shin
Ankle
Foot
Trunk

$\begin{array}{ll}\text { Yes } & \text { No } \\ \text { Yes } & \text { No }\end{array}$

Please check all categories that apply to your injury

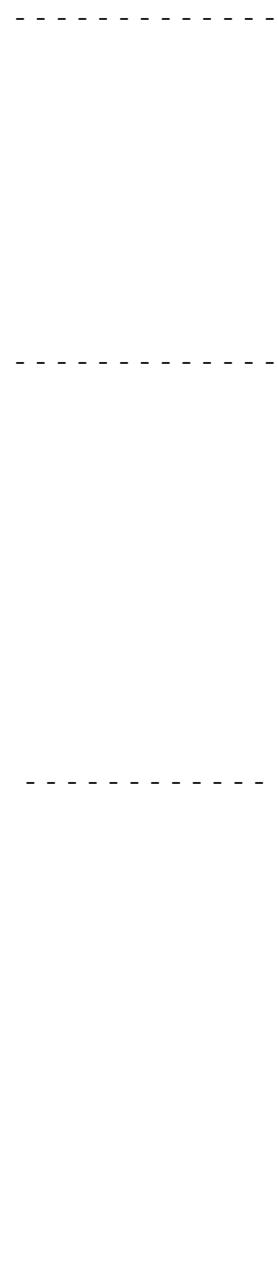

Medical Attention Received

None

Wound cleaning

Bandaid

Gauze

Athletic tape

Ointment

Cold compress/ice

Splint/brace

Stabilized for transport

Ambulance

Epi pen

Medication - pain relief

Medication - stomach

Rehydration

Nutrition

Other (please list below) 
Appendix 3. Medical supplies checklist

Is an Emergency Action Plan in place? If so please describe below or attach:

How far away is the nearest hospital?

Have hospitals been notified of this event?

Are there provisions for evacuating injured riders from the trail? If so please describe

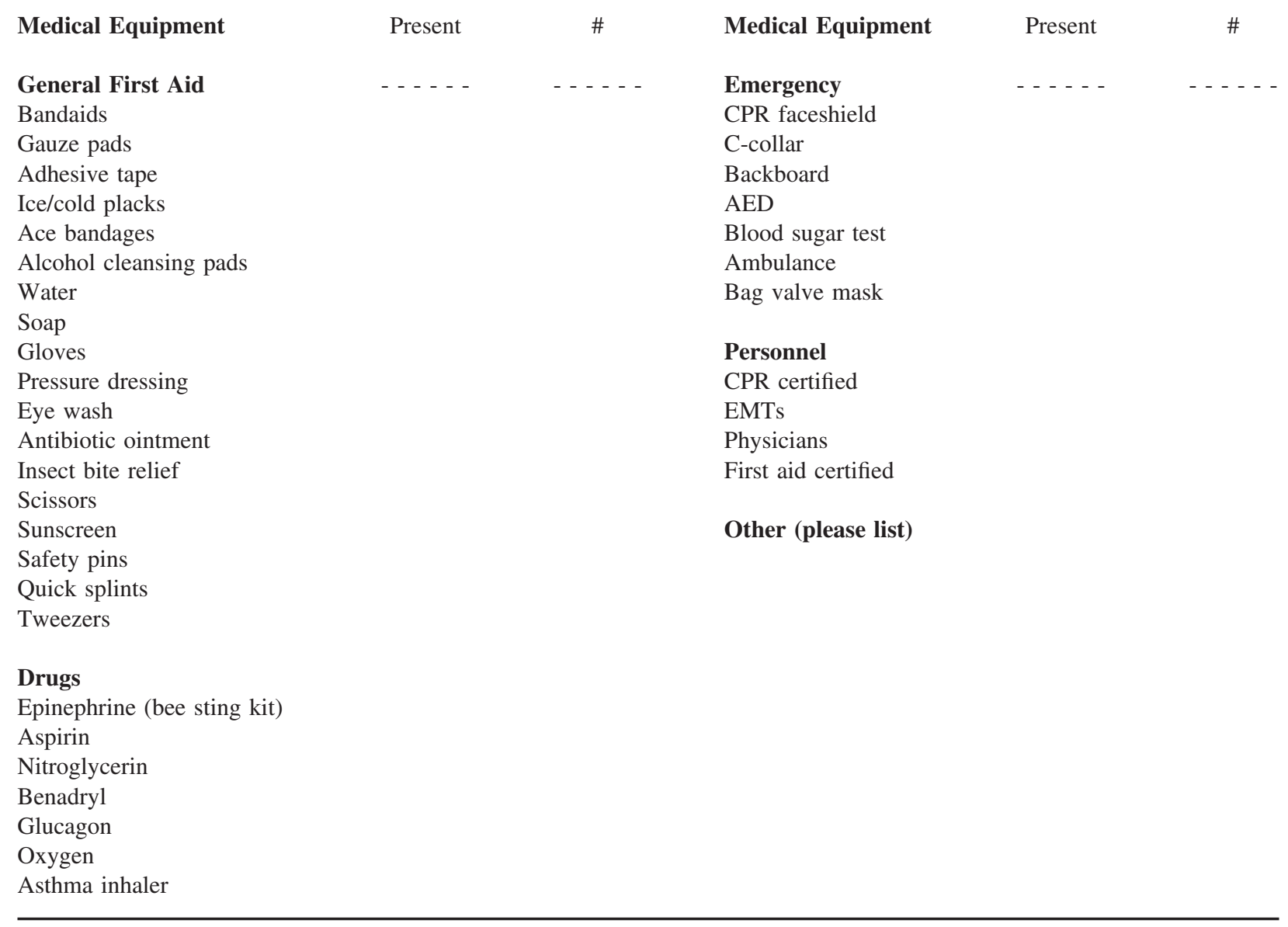

